\title{
Cardiac Computed Tomography - More Than Coronary Arteries? A Clinical Update
}

\section{Kardinale CT: Mehr als nur Koronarien? Ein Abgleich mit dem Alltag}

Authors

Jana Taron ${ }^{1,2}$, Borek Foldyna', Parastou Eslami' ${ }^{1}$, Udo Hoffmann¹, Konstantin Nikolaou², Fabian Bamberg ${ }^{3}$

Affiliations

1 Cardiac MR PET CT Program, Massachusetts GeneralHospital - Harvard Medical School, Boston, United States

2 Department of Diagnostic and Interventional Radiology, University-Hospital Tübingen, Germany

3 Department of Diagnostic and Interventional Radiology, Medical Center - University of Freiburg, Faculty of Medicine, University of Freiburg, Germany

Key words

cardiac, CT-angiography, CT

received 29.11.2018

accepted 06.05.2019

Bibliography

DOI https://doi.org/10.1055/a-0924-5883

Published online: 27.6.2019

Fortschr Röntgenstr 2019; 191: 817-826

(C) Georg Thieme Verlag KG, Stuttgart · New York

ISSN 1438-9029

Correspondence

Dr. Jana Taron

Cardiac MR PET CT Program, Massachusetts General-

Hospital - Harvard Medical School, Boston, United States

Tel.: ++1/617/7261255

jtaron@mgh.harvard.edu

\section{ZUSAMMENFASSUNG}

Hintergrund Durch technischen Fortschritt und neue Entwicklungen sowie die verbreitete Anwendung minimalinvasiver Verfahren, welche einer prä-interventionellen Planung bedürfen, ist die kardiale Computertomografie (CT) zu einer weit verbreiteten und vielseitig angewendeten Methode geworden, die zunehmend über die traditionelle koronare CT-Angiografie (CTA) hinausreicht.

Methode Dieser Übersichtsartikel stellt eine Zusammenfassung der aktuellen Literatur zur kardialen Computertomografie dar. Ziel dieser Übersicht ist es, die derzeitigen Leitlinien aufzuführen sowie aktuelle Indikationen und neue Entwicklungen im Bereich der kardialen CT, insbesondere im Rahmen extrakoronarer Applikationen, zu beleuchten.

Ergebnisse und Schlussfolgerung Nach aktuellen Leitlinien ist die Durchführung der kardialen CT u. a. zur Evaluation koronarer Herzerkrankungen, zur Darstellung kardialer und extrakardialer Anatomie sowie - unter bestimmten Voraussetzungen - zur Funktionsanalyse indiziert. Neben der koronaren CTA ist es durch neue technische Entwicklungen möglich, CT-gestützt eine fraktionelle Flussreserve (CT-FFR) zu berechnen. Zudem ermöglicht die kardiale CT Funktionsund Perfusionsuntersuchungen des linksventrikulären Myokards sowie prä-interventionelle Bildgebung insbesondere im Rahmen von Herzklappenerkrankungen oder vor Pulmonalvenenisolation zur Behandlung von Vorhofflimmern. Insbesondere diese extrakoronaren Anwendungen sind von wachsendem Interesse im klinischen Alltag und eine zunehmende Nachfrage ist in nächster Zeit zu erwarten.

\section{Kernaussagen:}

- Koronare Bildgebung ist weiterhin der Hauptbestandteil der kardialen $\mathrm{CT}$.

- Neue Techniken erlauben die CT-gestützte Berechnung von Flussdynamiken (CT-FFR).

- Kardiale CT kann wichtige Informationen über das linksventrikuläre Volumen, Funktion und Perfusion liefern.

- CT ist ein Kernelement für die prä-interventionelle Planung vor minimalinvasivem Katheter-gestütztem Herzklappenersatz sowie Pulmonalvenenisolation zur Behandlung von Vorhofflimmern.

\section{ABSTRACT}

Background Rapid improvement of scanner and postprocessing technology as well as the introduction of minimally invasive procedures requiring preoperative imaging have led to the broad utilization of cardiac computed tomography (CT) beyond coronary CT angiography (CTA).

Method This review article presents an overview of recent literature on cardiac CT. The goal is to summarize the current guidelines on performing cardiac CT and to list established as well as emerging techniques with a special focus on extracoronary applications.

Results and Conclusion Most recent guidelines for the appropriate use of cardiac CT include the evaluation of coronary artery disease, cardiac morphology, intra- and extracardiac structures, and functional and structural assessment of the myocardium under certain conditions. Besides coronary CTA, novel applications such as the calculation of a CT-derived fractional flow reserve (CT-FFR), assessment of myocardial function and perfusion imaging, as well as pre-interventional planning in valvular heart disease or prior pulmonary vein 
ablation in atrial fibrillation are becoming increasingly important. Especially these extracoronary applications are of growing interest in the field of cardiac CT and are expected to be gradually implemented in the daily clinical routine.

\section{Key Points:}

- Coronary artery imaging remains the main indication for cardiac CT

- Novel computational fluid dynamics allow the calculation of a CT-derived fractional flow reserve in patients with known or suspected coronary artery disease
- Cardiac CT delivers information on left ventricular volume as well as myocardial function and perfusion

- $\mathrm{CT}$ is the cardinal element for pre-interventional planning in transcatheter valve implantation and pulmonary vein isolation

\section{Citation Format}

- Taron J, Foldyna B, Eslami P et al. Cardiac Computed Tomography - More Than Coronary Arteries? A Clinical Update. Fortschr Röntgenstr 2019; 191: 817-826

\section{Introduction}

Cardiovascular disease (CVD) is the leading cause of mortality worldwide. According to the European Cardiovascular Disease Statistics 2012 report, CVD and coronary heart disease (CHD) account for over 4 million deaths (42\% of all deaths) in Europe each year, and the impact of mortality and morbidity on European society and healthcare systems remains at a challenging level [1].

Not surprisingly, coronary imaging has been the main focus of cardiac computed tomography (CT) with its main indication still being "known or suspected coronary artery disease" - according to the European Society of Cardiac Radiology Cardiac MR/CT registry 2018 [2]. Rapid developments in scanner technology and acquisition protocols have made cardiac CT a safe, reliable, and widely applicable tool for coronary imaging [3, 4]. Innovations and advanced post-processing tools have generated increasing potential for applications beyond the anatomical imaging of coronary arteries including functional and structural assessment [5]. Furthermore, there has been an increasing demand to use cardiac $\mathrm{CT}$ for pre-interventional planning in minimally invasive procedures such as transcatheter valve implantation, mitral valve repair, and pulmonary vein ablation [6-8]. As all of these applications are expected to gain increasing importance in the clinical routine, this review intends to give an overview of the current use of cardiac CT as well as emerging techniques with a specific focus on applications beyond coronary arteries and their potential for future clinical application.

\section{Current Guidelines for the Appropriate Use of Cardiac CT}

As with all techniques using ionizing radiation, patient safety and risk/benefit assessments are crucial elements which need to be considered when applying CT in clinical settings. Therefore, over the past years, several guidelines for the appropriate use of cardiac CT have been issued by different societies to guide decision making [9-13].

Dependent on the patient's risk profile and previous test results, ruling out/detecting coronary artery disease (CAD) in symptomatic or asymptomatic patients without previously diagnosed heart disease or in patients prior to "noncoronary cardiac surgery" [9] is one of the main indications of cardiac CT [9]. Non-contrast cardiac CT allows the quantification of coronary calcification (to determine a calcium score/Agatston score [14]) at very lowradiation doses $(<1 \mathrm{mSv})$. This score serves for further risk stratification as patients with a calcium score of zero present a very low risk for adverse cardiac events, whereas the presence of calcifications indicates an elevated risk of events in the future $[15,16]$.

While the absence of coronary calcification does not entirely rule out the presence of CAD, coronary computed tomography angiography (CTA) can reliably detect atherosclerotic plaque as well as subsequent luminal narrowing $[3,4]$.

Functional assessment, specifically of the left ventricle, is recommended in patients with heart failure, post-myocardial infarction, or inconclusive images from prior noninvasive testing, while right ventricular function plays an important role in arrhythmogenic right ventricular dysplasia [9]. Functional and structural assessment is intended for "adult congenital heart disease" [9], native/prosthetic valves suspicious for dysfunction, the anatomy of pulmonary or coronary veins before intervention, or the visualization of bypass grafts $[9,11]$.

As outlined above, coronary artery imaging and specific functional analyses are well implemented in clinical guidelines, whereas several secondary analyses of the primary CT-data especially with regard to function and structure - are currently predominant in research rather than the daily routine. However, with the continuous evolution of CT imaging towards physiological assessment raising the demand for these techniques, a broader spectrum of clinical indications of cardiac CT can be expected within the next years.

\section{Cardiac CTA - Image Acquisition}

Apart from non-contrast cardiac CT for the detection of coronary artery calcifications, coronary CTA is the workhorse of cardiac imaging and prerequisite for most post-processing analyses.

The acquisition of a coronary CTA ( $\triangleright$ Fig. 1 ) is performed ECGgated either in a retrospective or prospective way. The retrospectively ECG-gated approach captures the heart throughout the whole cardiac cycle, acquiring images at multiple cardiac phases and, thus, delivering robust, high-quality images even at high heart rates, yet at increased radiation exposure compared to prospective modes. For prospectively ECG-gated scans, sequential and high-pitch helical techniques are available, which are chosen 

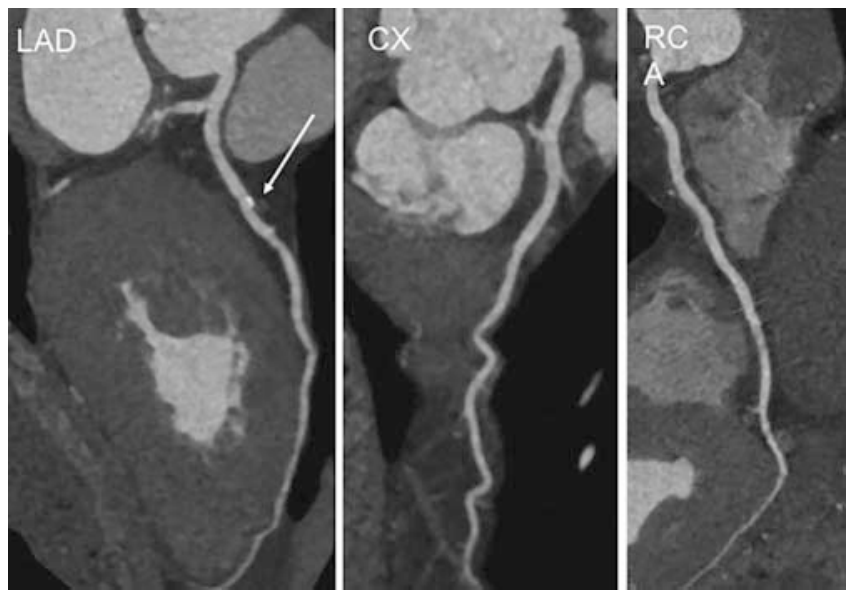

- Fig. 1 Coronary CTA of a 62-year-old patient with a non-obstructive calcified plaque in the proximal LAD. CX and RCA were patent on images. CTA: computed tomography angiography, CX: circumflex artery, LAD: left anterior descending Artery, RCA: right coronary artery.

- Abb. 1 Koronare CTA eines 62-jährigen Patienten mit nicht obstruktivem kalzifiziertem Plaque des proximalen Ramus interventricularis anterior. Ramus circumflexus und Arteria coronaria dextra waren durchgängig. CTA: Computertomografie-Angiografie.

depending on heart rate and rhythm, as well as patient habitus (with maximum established thresholds of 65 heartbeats/minute, sinus rhythm and a body-mass index $<30 \mathrm{~kg} / \mathrm{m}^{2}$ ). The sequential mode acquires images of different anatomic regions during preselected cardiac phases, the so-called "step-and-shoot" method, whereas high-pitch helical scans cover the entire heart with a single gantry rotation, so that the image is obtained in a single cardiac cycle $[17,18]$. The latter is associated with a drastic dose reduction to an average effective dose of 1.2-3.2 mSV [19] - in comparison, modern retrospective spiral acquisitions comprise 5.7-10.7 mSV [20], and diagnostic invasive coronary angiography typically uses 2-7 mSV [21] - yet requires optimal timing during acquisition to ensure a motion-free image. Another limitation of this approach is the inability to assess cardiac function, which is done in retrospectively gated scans [22] and will be further addressed in the corresponding section.

\section{Cardiac CT in Functional Imaging}

\section{Fractional Flow Reserve (FFR)}

Several studies in the past years have demonstrated the high diagnostic value of coronary CTA in patients with acute and stable anginal symptoms [3, 4, 23-27].

In this context, coronary CTA has proven to have a high negative predictive value for the occurrence of acute coronary events in patients with acute chest pain [24] and has been evaluated as safe for ruling out CAD in low/intermediate risk patients with stable angina and suspected coronary syndrome [23]. Also, most recent long-term results in patients with stable chest pain confirmed that coronary CTA in addition to standard care versus standard care alone leads to a significant decrease in death from coronary heart disease and nonfatal myocardial infarction without resulting in an increase in invasive catheterization and revascularization [25]. However, the extent of coronary plaque on CTA may not always correlate well with the functional significance of a lesion as measured by invasive FFR [28], which is one of the gold standard methods for identifying such lesions and is considered a class lla recommendation for admitting a patient to coronary revascularization [29]. In fact, the positive predictive value of coronary CTA in the evaluation of functionally significant lesions (defined by $>50 \%$ luminal narrowing) compared to FFR (defined by a ratio $\leq 0.75$ ) demonstrated a sensitivity of $79 \%$ and a specificity of $86 \%$ [30], making management of patients with stenoses on CTA difficult [31].

In this respect, novel computational fluid dynamic (CFD) modeling techniques now allow the noninvasive calculation of a CT-derived FFR by using coronary CTA-images to evaluate the functional significance of a given lesion without additional application of contrast or vasodilator agents. For example, HeartFlow Inc. (Redwood City, California, USA) is a company approved by the US Food and Drug Administration (FDA) to provide the CT-FFR value in an online service by calculating the values three-dimensionally similar to what is described in $>$ Fig. 2. Alternatively, Siemens Healthcare (Forchheim, Germany) recently developed a technique for on-site workstations to calculate CT-FFR values using a 1D approach, which, however, is currently only available for research purposes [32].

Thus far, several studies have described good correlations of both computational methods to invasive FFR when compared to CTA alone [33-35]. For instance, a study by Norgaard et al. demonstrated a strong correlation with coronary CTA $(r=0.82)$ with a sensitivity and specificity in detecting a functionally significant lesion of $86 \%$ and $79 \%$, respectively [34]. Moreover, Ko et al. reported that CTFFR compared to invasive measurements had a higher specificity ( $87 \%$ vs. $74 \%$ ) with similar sensitivity ( $78 \%$ vs. $79 \%$ ) [35].

While comparative studies demonstrate encouraging results, the long-term outcomes of FFR-guided interventions, in general, appear to be unclear. Recently presented data from the FUTURE trial comparing FFR-guided intervention to traditional angioplasty in patients with acute and stable chest pain and multivessel disease ( $>50 \%$ stenosis) suggests a higher mortality rate in the FFR group (interim analysis at 12 months: $4 \%$ all-cause death in the FFR group versus $2 \%$ in angioplasty group, $p=0.02$ ), which led the investigators to end enrollment prematurely [36]. This is a very critical aspect warranting additional investigation. With regard to these results and the currently limited availability of CT-FFR calculations, further research on clinical performance and cost-effectiveness is needed.

\section{Myocardial Perfusion Imaging}

The detection of myocardial ischemia is of utmost importance for the diagnosis, treatment, and prognostic outcome of patients and has been the method of choice for viability assessment in obstructive atherosclerosis [37]. Currently, stress-induced electrocardiogram (ECG), echocardiography, cardiac magnetic resonance imaging (MRI), as well as single photon emission computed tomography (SPECT) and positron emission tomography (PET) are the gold standard methods for the assessment of LV myocar- 


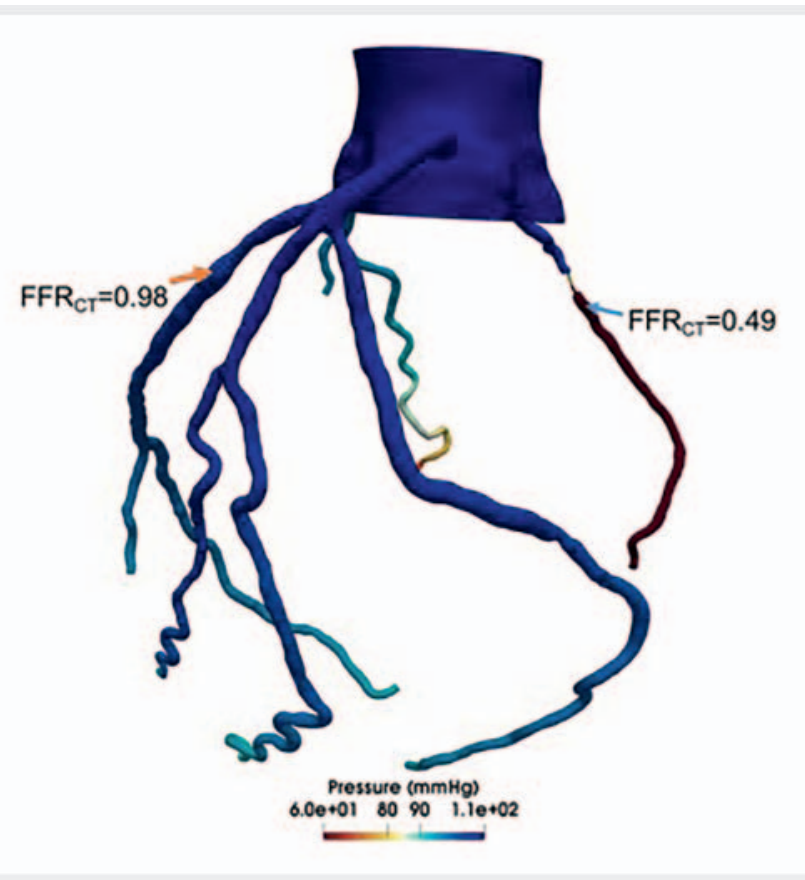

Fig. 2 64-year-old male patient with a two-day history of episodes of unstable angina. He underwent coronary CTA which demonstrated moderate luminal narrowing of the LAD with a calculated CT-FFR of 0.98 (orange arrow) and subtotal occlusion of RCA with a CT-FFR of 0.49 (blue arrow). Representative case performed by Dr. Eslami: CFD patient-specific models were created to simulate hemodynamics in coronary arteries. CT-FFR was calculated in postprocessing before and after the lesion using a spherical probe with a radius of $0.005 \mathrm{~cm}$ to measure the pressure. CFD: computational fluid dynamics, CTA: computed tomography angiography, CT-FFR: CT-derived fractional flow reserve, LAD: left anterior descending artery, RCA: right coronary artery.

- Abb. 2 64-jähriger Patient mit seit 2 Tagen bestehenden Episonden einer instabilen Angina pectoris. Die koronare CTA zeigte eine moderate luminale Einengung des Ramus interventricularis mit einer berechneten CT-FFR von 0,98 (orangener Pfeil) und einem subtotalen Verschluss der Arteria coronaria dextra mit einer CT-FFR von 0,49 (blauer Pfeil). Repräsentativer Fall berechnet von Dr. Eslami: Patientenspezifische CFD-Modelle zur Simulation der hämodynamischen Verhältnisse der Koronararterien wurden erstellt, die CT-FFR wurde mittels post-processing proximal und distal der Läsion durch eine sphärische Messsonde mit einem Radius von $0,005 \mathrm{~cm}$ zur Druckmessung berechnet. CFD: Computational Fluid Dynamics, CTA: Computertomografie-Angiografie, CT-FFR: CT-basierte fraktionelle Flussreserve.

dial viability [38]. Yet, none of these techniques can assess myocardial perfusion while at the same time delivering anatomical information on coronary arteries, which is a hallmark of CT. The combination of functional and anatomical information can be especially important as a high number of events have been shown to occur in patients with non-obstructive CAD (1-69\% stenosis), which is not captured by perfusion imaging alone [39].

The theory behind CT perfusion imaging is the distribution of iodinated contrast media through the myocardium by the coronary arteries. Thus, first-pass perfusion defects - as present in high-
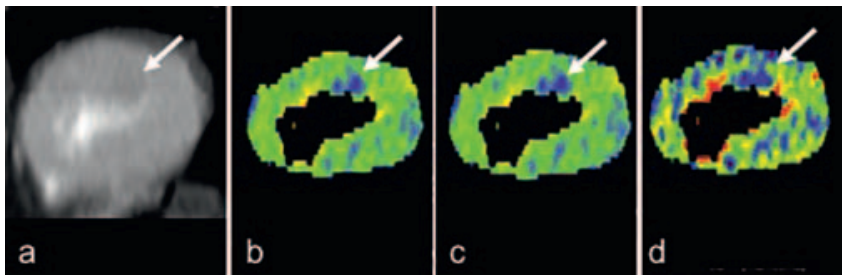

- Fig. 3 54-year-old male patient with history of diabetes mellitus type 2, hypertension, hyperlipidemia, and a family history of CAD as well as know CAD in the LAD. The patient presented with stable anginal symptoms. Coronary CTA and CT perfusion imaging were performed. CTA demonstrated $70 \%$ stenosis in the medial LAD, perfusion imaging showed a subendocardial perfusion defect in the LAD territory (white arrow). a temporal average, $\mathbf{b}$ myocardial blood flow, $\mathbf{c}$ myocardial blood volume, $\mathbf{d}$ perfused capillary blood volume, CAD: coronary artery disease, CTA: computed tomography angiography, LAD: left anterior descending artery.

Abb. 3 54-jähriger Patient mit Diabetes mellitus Typ 2, Hypertension, Hyperlipidämie, positiver Familienanamnese einer KHK und einer bekannter KHK des Ramus interventriucularis. Der Patient zeigte Symptome einer stabilen Angina pectoris, worauf eine koronare CTA sowie eine CT-Perfusion durchgeführt wurden. In der CTA zeigte sich eine $70 \%$ ige Stenose im mittleren Abschnitt des Ramus interventricularis mit Perfusionsdefekt im entsprechenden Versorgungsgebiet (weißer Pfeil) in der Perfusionsmessung. a Zeitmittelwert, b myokardialer Blutfluss, c myokardiales Blutvolumen, d perfundiertes kapillares Blutvolumen. CTA: ComputertomografieAngiografie, KHK: koronare Herzerkrankung.

grade stenosis or occlusions - are visualized as areas of hypoattenuation in the myocardial muscle ( $\triangleright$ Fig. 3) [40].

In general, CT myocardial perfusion imaging can be performed at rest or under pharmacologically induced stress in two different ways: static versus dynamic. Static image acquisition takes place at the time of maximum contrast concentration in the myocardium of the left ventricle allowing a "visual qualitative assessment of a single snapshot of myocardial iodine contrast attenuation" [40]. In dynamic perfusion imaging, the scan is repeated sequentially during contrast passage through the myocardium, thus, allowing direct measurement of myocardial perfusion. While the correct timing of this technique is less crucial, its limitations are the risk of motion artifacts (caused by both motion of the patient and the heart) as well as increased radiation exposure compared to static image acquisition $[40,41]$.

The introduction of dual-source scanners permits a third approach to perform CT perfusion imaging (either static or dynamic) by combining two different tube voltages, and thus, two different energy spectra of CT photons - typically $100 \mathrm{kV}$ and $140 \mathrm{kV}[42,43]$. As CT attenuation values for different tissues are specific depending on the energy spectrum used, dual-energy CT improves tissue characterization (especially of iodine) [43], rendering the differentiation of iodine attenuation and cardiac tissue possible. lodine distribution in the myocardium can be mapped (usually in a color-coded manner) and superimposed on the naïve image to aid identification of perfusion deficits [42]. Another feature of dual-energy $\mathrm{CT}$ is the simultaneous acquisition of two data sets (high- and low-kV). While the low-kV images present better tissue contrast (as they are closer to the k-edge of 
iodine), the consecutive high noise limits its routine acquisition in single-source scanning. Yet, the improved differentiation of iodine uptake in these images is a potential advantage, which yielded a higher sensitivity ( $80 \%$ vs. $77 \%$ ) in a study investigating $100 \mathrm{kV}$ images compared to a virtual $120 \mathrm{kV}$ series in the detection of chronic myocardial infarction [43].

In terms of radiation exposure, recent literature reports very low radiation doses of just $2.5 \mathrm{mSv}$ in stress/rest perfusion using a 128-slice dual-source scanner [44].

Image analysis in CT perfusion imaging is performed on multiplanar reconstructed images in short axis stacks of the left ventricle as well as in the orthogonal axis. The location of mal-perfused areas is described using the standard 17-segment model [41]. In static imaging, evaluation is mostly performed visually. While an option to evaluate the images semi-quantitatively (by calculating the ratio of subendocardial and subepicardial enhancement) exists, the visual approach has been described as more accurate [41]. In dynamic imaging, the semiquantitative evaluation can be performed by calculating a time-attenuation curve [40].

Several studies have addressed the additional value and diagnostic accuracy of CT perfusion versus CT angiography alone. In a meta-analysis, investigating 12 studies with a total of 920 patients, CT perfusion showed a "favorable diagnostic performance" [45] when compared to invasive coronary catheterization with a small increase in specificity (without altering the sensitivity or overall performance) [45]. A multicenter study including 381 patients found that coronary CTA in combination with static CT perfusion imaging was able to correctly identify patients with known $C A D \geq 50 \%$ (results from invasive coronary angiography) and perfusion defects as detected by stress single photon emission computed tomography [46]. Osawa and colleagues further described a significant added value of CT perfusion (under resting conditions) to coronary CTA in the diagnosis of CAD with an increase of the area under the receiver operating characteristic curve from 0.84 to $0.89(p=0.02)$ [47]. Also in single-energy studies, several investigations report an incremental diagnostic value when combining dual-energy perfusion imaging with coronary CTA using SPECT or invasive coronary angiography as a reference [48-50]. Additionally, there is evidence that the dual-energy approach may be favorable in tissue characterization when compared to singleenergy CT (especially when using reconstructed monochromatic images at $70 \mathrm{kV}$ to eliminate beam-hardening artifacts) [51].

\section{Viability and Fibrosis}

Secondly to first-pass perfusion imaging, delayed enhancement imaging (performed 5-10 min after contrast injection) has been introduced. With this, cardiac CT has proven feasible in viability assessment (i. e., the detection of necrosis, fibrosis, and microvascular obstruction) in a selected patient population, which has thus far been a domain of cardiac MRI. An infarcted territory can be characterized based on hyper- and hypoenhancement on delayed enhancement images signaling an infarcted territory or microvascular obstruction. In the case of hyperenhancement in acute infarction, membrane dysfunction lets iodine molecules pass into the intracelIular space where contrast accumulates. Hyperenhancement in scar tissue, however, is believed to be caused by an increase of the inter- cellular space due to cell necrosis. Microvascular obstruction, on the other hand, appears as hypoattenuation due to blockage of capillaries caused by cell debris despite restored flow [52].

While focal myocardial scar tissue can be reliably detected on CT images, diffuse myocardial fibrosis has mainly been quantified using MRI (specifically T1-mapping) [53]. However, with the increasing use of CT, several groups have developed methods to quantify diffuse tissue scarring using CT images [54-56]. The idea behind both techniques is the calculation of the extracellular volume (ECV) fraction of the myocardium (representing equal distribution of contrast material between muscle and blood on delayed enhancement images), which is increased in myocardial fibrosis and associated with various cardiomyopathies and heart failure $[54,57,58]$.

Nacif et al. have published a method to identify myocardial fibrosis on cardiac CT using unenhanced and contrast-enhanced images. For the calculation of ECV, HU attenuation values in the myocardium and blood pool were measured in pre- and postcontrast images and the ratio of these changes (change in myocardial attenuation/change in blood pool attenuation) was set in relation with the patient's hematocrit level. CT-obtained ECV values demonstrated good correlation with MRI measures $(r=0.82)$ and were elevated in patients with heart failure [54].

In a different approach, Lee et al. evaluated the feasibility of contrast-enhanced dual-energy CT for the quantification of myocardial fibrosis by measuring overlay attenuation values of the myocardium and blood pool on iodine attenuation maps. Again, the results were comparable with MRI, which served as a reference standard, and an increase in ECV was associated with cardiomyopathy (hypertrophic and dilated), amyloidosis, and sarcoidosis [55].

Overall, these results encourage the use of CT-based tissue characterization in the future.

\section{Cardiac Functional Imaging}

Especially in patients with chest pain but an uncertain diagnosis of an acute coronary syndrome, the detection of a dysfunctional myocardium is of high prognostic value and could guide further patient management [5]. Functional assessment is readily available for every retrospectively acquired ECG-gated cardiac CT examination. However, dedicated post-processing tools are needed for image analysis [17]. Previous studies have shown a close correlation between end-diastolic and end-systolic LV volume and ejection fraction and regional wall motion abnormalities [5] obtained by multislice CT compared to two-dimensional echocardiography, and acceptable correlation for the computed LV stroke volume [59]. While the temporal resolution of CT is still inferior to that of transthoracic echocardiography (TTE) (CT as low as $66 \mathrm{~ms}$ [60] vs. TTE < 5 ms [61]), limited echocardiographic windows are not an issue. Cury and colleagues described a comparable accuracy of CT (of $96 \%$ ) and TTE in the diagnosis of an acute myocardial infarction combined with higher interobserver reliability for the quantification of the ejection fraction in $\mathrm{CT}$ (interobserver reliability $C T r=0.83$, TTE $r=0.68$ ) [5]. In patients with acute chest pain, the CT LV function demonstrated an incremental value in the detection of an acute coronary syndrome with an $89 \%$ sensitivity and $86 \%$ specificity for significant stenosis (> $50 \%$ ) and a $60 \%$ sensitivity and an $86 \%$ specificity in patients with inconclusive coron- 

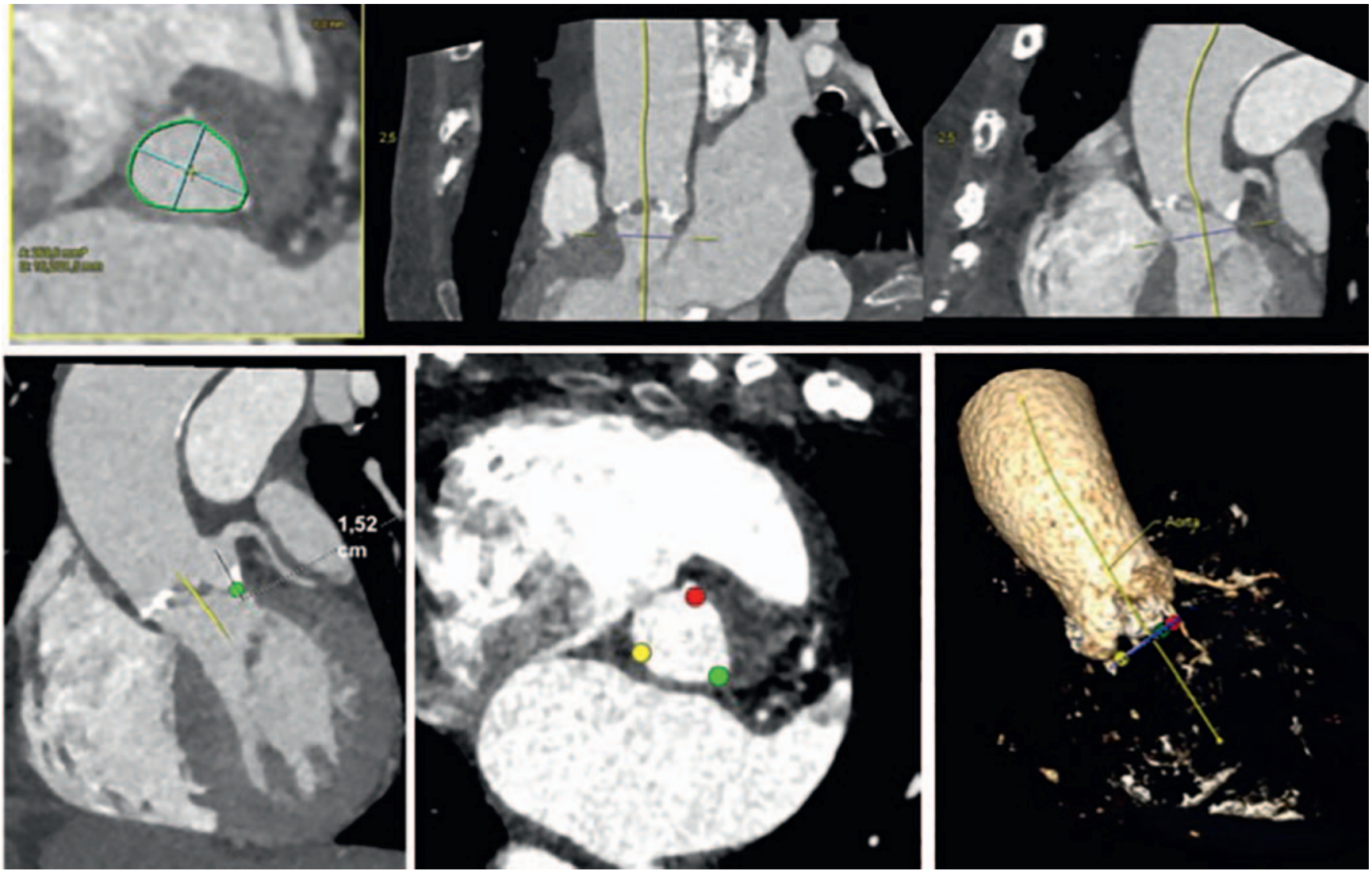

- Fig. 4 Images of an 87-year-old female patient scheduled for transcatheter aortic valve implantation. Measurements of aortic root and area of aortic annulus (with distance of annulus to ostium of coronary arteries) to ensure appropriate device selection.

- Abb.4 Bilder einer 87-jährige Patientin vor geplantem Katheter-gestützten Aortenklappenersatz. Messungen der Aortenwurzel und der Fläche des Anulus (mit Abstandsmessung vom Anulus zum Ostium der Koronararterien) zur Interventionsplanung.

ary CTA [62]. This is especially crucial in patients post-myocardial infarction as LV function is an important marker for prognosis and treatment [63].

For the assessment of right ventricular (RV) function, good opacification of the right ventricular lumen is required, which can be achieved by alternating the standard injection protocol (i. e., by extending the standard duration of contrast application or using multiphase protocols with a combination of contrast and saline flush) [64]. Results of RV lumen measurements and ejection fraction have demonstrated similar results in comparison to cardiac MRI [65].

While impairment of ventricular function often resembles global or later-stage disease (i. e., systolic heart failure), CAD, but also other cardiac diseases such as myocarditis can be limited to certain territories, leading to regional abnormalities. These regional functional impairments can be assessed using advanced secondary analyses including strain measurements (longitudinal, circumferential, and radial as well as sheer strain). Strain measurements are typically assessed with TTE or cardiac MRI (currently considered the gold standard), but practical and technical limitations have been hindering its implementation in clinical practice. Functional assessment on cardiac CT is rapidly evolving with comparable results to MRI measures in initial studies $[66,67]$. With the broad availability of CT scanners, fast acquisition times (compared to MRI studies) and a wider window (compared to TTE), CT strain measurements resemble a promising but still developing alternative given that dedicated software packages for evaluation are available $[66,67]$.

\section{Cardiac CT for Pre-Interventional Planning}

\section{Transcatheter Valve Implantation}

With the introduction of catheter-based minimally invasive methods to treat valvular disorders, this procedure has gained increasing interest throughout Europe in the past years. Transcatheter aortic valve implantation (TAVI), as well as transcatheter mitral valve implantation (TMVI), have become established alternatives to open heart surgery specifically for high-risk patients with symptomatic valve disease [6, 7]. For instance, in Germany the number of TAVI procedures has increased 20-fold from 2008 (with 637 procedures) to 2013 (with 13264 procedures), thus outnumbering surgical aortic valve replacements and becoming the most commonly performed procedure in the treatment of aortic valve stenosis in patients of age [68].

To be able to perform this intervention successfully, CT is essential for selecting suitable candidates, including assessment of the valvular anatomy and the peripheral vessels (as access 

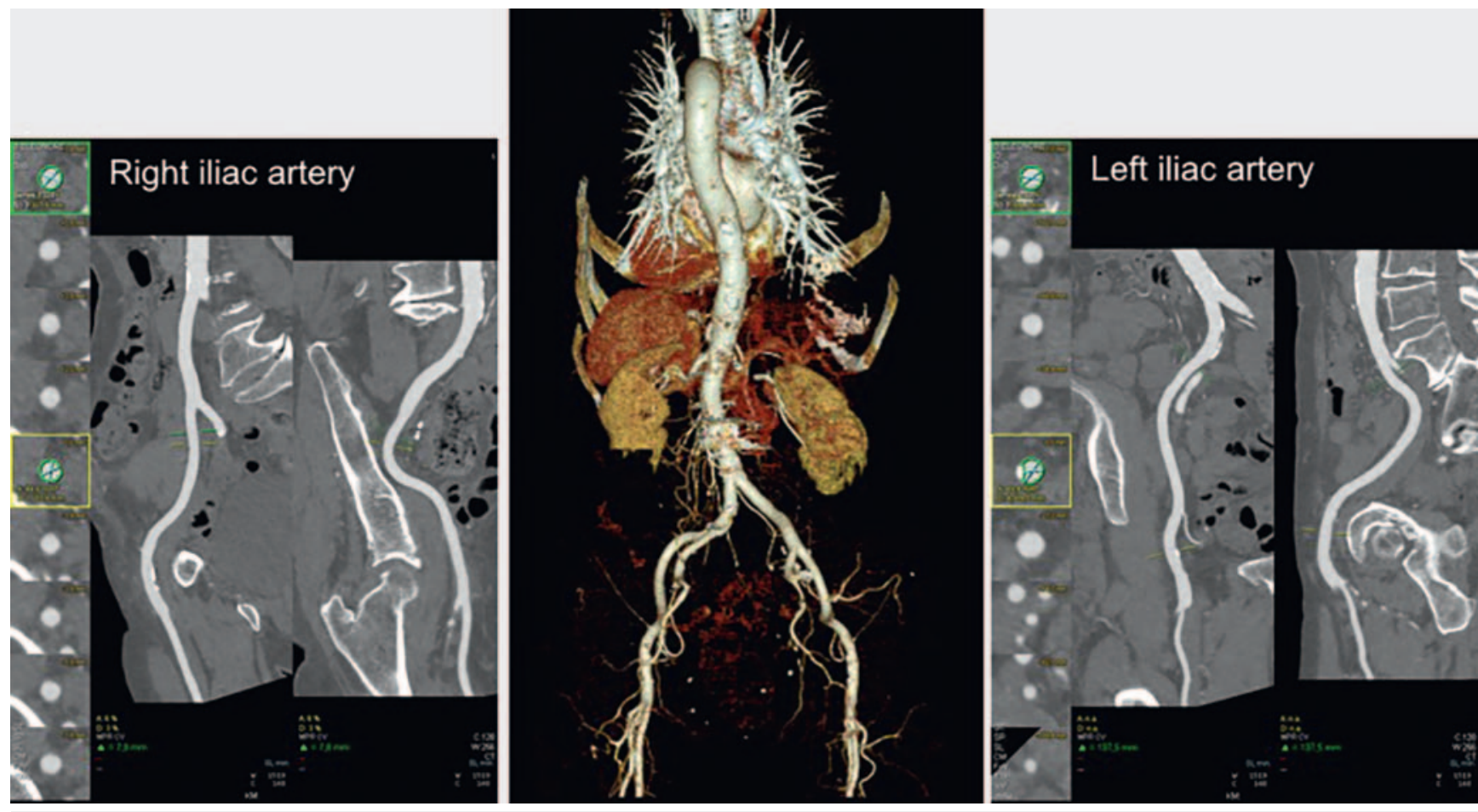

- Fig. 5 Images of the same 87-year-old female patient scheduled for transcatheter aortic valve implantation. 3D volume rendering technique of the vascular anatomy as well as 2D images of the iliac arteries to select the most suitable pathway to access. Measurements include the minimal and maximal vessel diameter.

- Abb.5 Bilder der gleichen 87-jährigen Patientin vor Katheter-gestütztem Aortenklappenersatz. 3D-Volume-Rendering-Technik der Gefäßanatomie sowie 2D-Bilder der lliakalarterien zur Interventionsplanung. Messungen beinhalten minimalen und maximalen Gefäßdurchmesser.

routes) for the lack of intraprocedural visualization. An expert consensus issued in collaboration with the American Heart Association (AHA) in 2012 recommends a multidetector system with 64 or more slices, high spatial resolution $(0.5-0.6 \mathrm{~mm})$ and a scan ranging from the ascending aorta to the iliofemoral branches. While image acquisition protocols may vary depending on site, vendor, and scanner, it is essential to capture the aortic root without motion artifacts using an ECG-synchronized mode. Assessment of the following vascular segments can be performed in a non-gated fashion to reduce radiation dose and the amount of iodinated contrast material needed [13].

In aortic valve replacement, it is crucial to evaluate the aortic valve, aortic annulus, aortic root, ascending aorta, and the aortic run-offs to ensure appropriate prosthesis selection and the availability of sufficient access routes ( $\triangleright$ Fig. 4). Especially measuring the effective diameter of the aortic annulus (formed by the lowest points of each of the three aortic cusps and their connection to the wall of the left ventricular outflow tract) in an appropriate cardiac phase (late systole) is of importance, as the prosthesis is fitted to this ring-like structure [6, 69]. One advantage over the traditional measurements performed with 3D echocardiography (which only delivers a single diameter) is the possibility to assess the minimal as well as the maximal diameter and the area of the aortic annulus, which oftentimes resembles an oval shape. As this shape is likelier understood with multiple measurements, CT assessment may be beneficial in prosthesis sizing [13]. Furthermore, the distance from the aortic annulus to the ostia of the coronary arteries as well as the diameter of the ascending aorta are required for planning the intervention to avoid injury or occlusion [6]. Additionally, pre-procedural CT has been proven beneficial in determining optimal fluoroscopic angulations for an orthogonal view of the aortic valve leading to a significant reduction of contrast use during intervention [70].

In mitral valve replacement, it is especially important to pay close attention to the mitral annulus and mitral valve leaflets, the morphology of the papillary muscles and the anatomic relation to the left circumflex coronary artery and coronary sinus [7].

Mitral valve annuloplasty is another approach for transcatheter valve repair in patients with secondary mitral regurgitation, in which the septolateral diameter of the mitral annulus is reduced to improve leaflet coaptation [71]. Currently, different catheterbased devices for direct annuloplasty using a transvenous-transseptal or transarterial route are available. Again, pre-procedural CT imaging to screen for suitable anatomy and appropriate device selection is critical [72].

The overall strength of pre-procedural measurement with $\mathrm{CT}$ is the high spatial and temporal resolution and the unlimited availability of the data set once the $\mathrm{CT}$ images are acquired. Dedicated post-processing software allows the reconstruction of the images along predefined planes including left anterior oblique (LAO) and right anterior oblique (RAO) resembling angiographic planes [7]. To enable the surgeon to select the most suitable and safe path- 
way to access (i. e., transfemoral, transapical, subclavian or transaortic), the entire vascular system can be mapped three-dimensionally to visualize the course and tortuosity of vessels (from the aortic arch to the femoral arteries) and measure minimal and maximal vessel diameter to perform the intervention ( $\boldsymbol{F} \mathbf{F i g . 5}$ ). Furthermore, the aortic valve and vessel wall calcifications can be quantified, which may present contraindications for the implementation of certain devices [6, 7, 73, 74].

\section{Pulmonary Vein Isolation}

Pulmonary vein (PV) isolation is an established catheter ablation procedure in atrial fibrillation (AF) for patients with recurrent and drug-refractory symptoms [8]. AF is the most common cardiac arrhythmia affecting 2-3\% of the general population in Europe and North America with a prevalence of $10-17 \%$ in patients over the age of 80 and it significantly increases the risk of cardiac and non-cardiac deaths [75]. Common causes for AF include ectopic electrical foci in the atria or the muscular sleeves of the distal PV, of which $50 \%$ are located in the left superior PV. To isolate these foci by interrupting the conduction pathways, PV isolation has become an established non-surgical treatment option. Although pre-procedural planning can be performed with electrocardiography, pulmonary venography, or MRI, cardiac CT features numerous benefits compared to other imaging techniques. With volume rendering, a 3D-model of the left atrium and the PVs can be calculated to provide accurate 3D information. Furthermore, ostium size of the PV and its distance from the first side branch as well as the location of the esophagus, and vagal nerve structures can be determined, which is crucial to eliminate complications associated with this procedure. Lastly, CT images can be imported directly into the ablation workstations and fused with electrophysiology maps to guide the procedure and assure maximum success [76].

\section{Conclusion}

With CVD being the leading cause of mortality worldwide, coronary artery imaging has been the main focus of cardiac CT. However, with recent technical developments, cardiac CT is emerging beyond coronary imaging for functional and pre-interventional assessment. Innovations, rendering CT-derived FFR calculations and $\mathrm{CT}$ perfusion imaging possible, enable the noninvasive assessment of the functional significance of coronary lesions and help tackle significantly diseased coronary artery segments. Dual-energy, CT perfusion, and delayed-enhancement imaging allow CT-based tissue characterization and diagnosis of ischemia. Ventricular volume and function assessment as well as the emerging possibility to measure myocardial strain with CT are of significance in regional versus global disease. Ventricular volume is also an important marker for prognosis and treatment. Furthermore, cardiac CT has become a highly valuable tool for planning complex interventions. CT images provide accurate 3D anatomic models for pre-interventional planning of catheter-guided interventions such as TAVI, interventional mitral valve therapies, and PV isolation. While all of these techniques are of growing importance, on-site expertise as well as appropriate hardware and software for the acquisition and analysis of each CT data set is required.
It is expected that these techniques will be increasingly implemented in the clinical routine and that some indications such as the diagnosis of myocardial ischemia and viability might be redirected from MRI to cardiac CT within the next years.

\section{Conflict of interest}

Prof. Dr. Fabian Bamberg: Bayer Healthcare, speakers bureau and unrestricted research grant Siemens Healthineers, speakers bureau and unrestricted research grant.

Prof. Dr. Udo Hoffmann: Research support on behalf of the institution: KOWA, MedImmune, HeartFlow, Duke University (Abbott), Oregon Health \& Science University (AHA, 13FTF16450001), Columbia University (NIH, 5R01-HL109711), NIH/NHLBI 5K24HL113128, NIH/NHLBI 5T32HL076136, NIH/NHLBI 5U01HL123339Consulting Fees from: Abbott, Duke University (NIH), Recor Medical.

\section{Acknowledgement}

Jana Taron: Research fellowship Deutsche Forschungsgemeinschaft (TA 1438/1-1)

\section{References}

[1] Townsend N, Nichols M, Scarborough P et al. Cardiovascular disease in Europe - epidemiological update 2015. Eur Heart J 2015; 36: 2696-2705

[2] Registry CT. MR/CT-Registry in Europe 2017 ... be a part of it ! 2017. doi: https://www.mrct-registry.org/images/ESCR_2017_CardiacMRCTbooklet.pdf

[3] Hoffmann U, Truong QA, Schoenfeld DA et al. Coronary CT Angiography versus Standard Evaluation in Acute Chest Pain. N Engl J Med [Internet] 2012; 367: 299-308. doi:https://doi.org/10.1056/NEJMoa1201161

[4] Bittner DO, Ferencik M, Douglas PS et al. Coronary CT Angiography as a Diagnostic and Prognostic Tool: Perspective from a Multicenter Randomized Controlled Trial: PROMISE. Curr Cardiol Rep [Internet] 2016; 18: 40. doi:https://doi.org/10.1007/s11886-016-0718-9

[5] Cury RC, Nieman K, Shapiro MD et al. Comprehensive Assessment of Myocardial Perfusion Defects, Regional Wall Motion, and Left Ventricular Function by Using 64-Section Multidetector CT. Radiology [Internet] 2008; 248: 466-475. doi:http://www.ncbi.nlm.nih.gov/pmc/articles/ PMC2797649/

[6] Latsios G, Spyridopoulos TN, Toutouzas K et al. Multi-slice CT (MSCT) imaging in pretrans-catheter aortic valve implantation (TAVI) screening. How to perform and how to interpret. Hell ] Cardiol [Internet] 2018; 59: 3-7. doi:http://www.sciencedirect.com/science/article/pii/ S1109966617303998

[7] Natarajan N, Patel P, Bartel T et al. Peri-procedural imaging for transcatheter mitral valve replacement. Cardiovasc Diagn Ther 2016; 6: 144-159

[8] Jongbloed MRM, Dirksen MS, Bax JJ et al. Atrial fibrillation: multi-detector row $C T$ of pulmonary vein anatomy prior to radiofrequency catheter ablation - initial experience. Radiology 2005; 234: 702-709

[9] Taylor A], Cerqueira M, Hodgson JM et al. ACCF/SCCT/ACR/AHA/ASE/ ASNC/NASCl/SCAI/SCMR 2010 appropriate use criteria for cardiac computed tomography. A report of the American College of Cardiology Foundation Appropriate Use Criteria Task Force, the Society of Cardiovascular Computed Tomography, the. J Am Coll Cardiol 2010; 56: 1864-1894

[10] Montalescot G, Sechtem U, Achenbach S et al. 2013 ESC guidelines on the management of stable coronary artery disease: the Task Force on the management of stable coronary artery disease of the European Society of Cardiology. Eur Heart ] 2013; 34: 2949-3003 
[11] Members TF, Montalescot G, Sechtem U et al. 2013 ESC guidelines on the management of stable coronary artery diseaseThe Task Force on the management of stable coronary artery disease of the European Society of Cardiology. Eur Heart ] [Internet] 2013; 34: 2949-3003. doi:http://dx. doi.org/10.1093/eurheartj/eht296

[12] Stillman AE, Oudkerk M, Ackerman M et al. Use of multidetector computed tomography for the assessment of acute chest pain: a consensus statement of the North American Society of Cardiac Imaging and the European Society of Cardiac Radiology. Int J Cardiovasc Imaging 2007; 23: 415-427

[13] Holmes DR, Mack MJ, Kaul S et al. 2012 ACCF/AATS/SCAI/STS Expert Consensus Document on Transcatheter Aortic Valve Replacement. J Am Coll Cardiol [Internet] 2012; 59 (13): 1200-1254. doi:http://www. sciencedirect.com/science/article/pii/S0735109712000022

[14] Agatston AS, Janowitz WR, Hildner FJ et al. Quantification of coronary artery calcium using ultrafast computed tomography. J Am Coll Cardiol 1990; 15: 827-832

[15] Grundy SM, Stone NJ, Bailey AL et al. 2018 AHA/ACC/AACVPR/AAPA/ABC/ ACPM/ADA/AGS/APhA/ASPC/NLA/PCNA Guideline on the Management of Blood Cholesterol: Executive Summary: A Report of the American College of Cardiology/American Heart Association Task Force on Clinical Practice Guidelines. J Am Coll Cardiol 2018; pii: S0735-1097(18)39033-8

[16] Nasir K, Bittencourt MS, Blaha M] et al. Implications of Coronary Artery Calcium Testing Among Statin Candidates According to American College of Cardiology/American Heart Association Cholesterol Management Guidelines: MESA (Multi-Ethnic Study of Atherosclerosis). J Am Coll Cardiol 2015; 66: 1657-1668

[17] Sun Z. Multislice CT angiography in cardiac imaging: prospective ECG-gating or retrospective ECG-gating? Biomed Imaging Interv ] [Internet] 2010; 6: e4. doi:http://www.ncbi.nlm.nih.gov/pmc/articles/PMC3097791/

[18] Halliburton SS, Abbara S, Chen MY et al. SCCT guidelines on radiation dose and dose-optimization strategies in cardiovascular CT. J Cardiovasc Comput Tomogr [Internet] 2011; 5: 198-224. doi:https://www.ncbi. nlm.nih.gov/pubmed/21723512

[19] Hosch W, Hofmann NP, Mueller D et al. Body mass index-adapted prospective coronary computed tomography angiography. Determining the lowest limit for diagnostic purposes. Eur ] Radiol [Internet] 2013; 82: e232-e239. doi:http://10.0.3.248/j.ejrad.2012.12.013

[20] Fink C, Krissak R, Henzler T et al. Radiation Dose at Coronary CT Angiography: Second-Generation Dual-Source CT Versus Single-Source 64-MDCT and First-Generation Dual-Source CT. Am J Roentgenol [Internet] 2011; 196: W550-W557. doi:https://doi.org/10.2214/Am J Roentgenol.10.5153

[21] Einstein AJ, Moser KW, Thompson RC et al. Radiation dose to patients from cardiac diagnostic imaging. Circulation 2007; 116: 1290-1305

[22] Bastarrika G, Lee YS, Huda W et al. CT of coronary artery disease. Radiology 2009; 253: 317-338

[23] Litt HI, Gatsonis C, Snyder B et al. CT Angiography for Safe Discharge of Patients with Possible Acute Coronary Syndromes. N Engl ] Med [Internet] 2012; 366: 1393-1403. doi:https://doi.org/10.1056/NEJMoa1201163

[24] Hoffmann U, Bamberg F, Chae CU et al. Coronary Computed Tomography Angiography For Early Triage of Patients with Acute Chest Pain The Rule Out Myocardial Infarction Using Computer Assisted Tomography (ROMICAT) Trial. J Am Coll Cardiol [Internet] 2009; 53: 16421650. doi:http://www.ncbi.nlm.nih.gov/pmc/articles/PMC2747766/

[25] Newby DE, Adamson PD, Berry C et al. Coronary CT Angiography and 5-Year Risk of Myocardial Infarction. N Engl J Med 2018; 379: 924-933

[26] Douglas PS, Hoffmann U, Patel MR et al. Outcomes of anatomical versus functional testing for coronary artery disease. N Engl J Med 2015; 372: 1291-1300

[27] CT coronary angiography in patients with suspected angina due to coronary heart disease (SCOT-HEART): an open-label, parallel-group, multicentre trial. Lancet [Internet] 2015; 385: 2383-2391. doi:https:// doi.org/10.1016/S0140-6736(15)60291-4
[28] Rossi A, Papadopoulou SL, Pugliese F et al. Quantitative computed tomographic coronary angiography: does it predict functionally significant coronary stenoses? Circ Cardiovasc Imaging 2014; 7: 43-51

[29] Windecker S, Kolh P, Alfonso F et al. 2014 ESC/EACTS Guidelines on myocardial revascularization: The Task Force on Myocardial Revascularization of the European Society of Cardiology (ESC) and the European Association for Cardio-Thoracic Surgery (EACTS)Developed with the special contribution o. Eur Heart J 2014; 35: 2541-2619

[30] Sarno G, Decraemer I, Vanhoenacker PK et al. On the inappropriateness of noninvasive multidetector computed tomography coronary angiography to trigger coronary revascularization: a comparison with invasive angiography. JACC Cardiovasc Interv 2009; 2: 550-557

[31] Lu MT, Ferencik M, Roberts RS et al. Noninvasive FFR Derived From Coronary CT Angiography: Management and Outcomes in the PROMISE Trial. JACC Cardiovasc Imaging 2017; 10: 1350-1358

[32] Nakanishi R, Budoff MJ. Noninvasive FFR derived from coronary CT angiography in the management of coronary artery disease: technology and clinical update. Vasc Health Risk Manag 2016; 12: 269-278

[33] Coenen A, Lubbers MM, Kurata A et al. Fractional flow reserve computed from noninvasive $C T$ angiography data: diagnostic performance of an on-site clinician-operated computational fluid dynamics algorithm. Radiology 2015; 274: 674-683

[34] Norgaard BL, Leipsic J, Gaur S et al. Diagnostic performance of noninvasive fractional flow reserve derived from coronary computed tomography angiography in suspected coronary artery disease: the NXT trial (Analysis of Coronary Blood Flow Using CT Angiography: Next Steps). J Am Coll Cardiol 2014; 63: 1145-1155

[35] Ko BS, Cameron JD, Munnur RK et al. Noninvasive CT-Derived FFR Based on Structural and Fluid Analysis: A Comparison With Invasive FFR for Detection of Functionally Significant Stenosis. JACC Cardiovasc Imaging [Internet] 2017; 10: 663-673. doi:http://www.sciencedirect.com/science/article/pii/S1936878X1630626X

[36] AHA 2016: Mortality rate with FFR-guided treatment of multivessel disease is unexpectedly high [Internet]. 2016. [cited 2019 Mar 1] doi:https://cardiovascularnews.com/aha-2016-mortality-rate-with-ffrguided-treatment-of-multivessel-disease-is-unexpectedly-high/

[37] George RT, Arbab-Zadeh A, Cerci RJ et al. Diagnostic performance of combined noninvasive coronary angiography and myocardial perfusion imaging using 320-MDCT: the CT angiography and perfusion methods of the CORE320 multicenter multinational diagnostic study. Am J Roentgenol [Internet] 2011; 197: 829-837. doi:https://www.ncbi.nlm. nih.gov/pubmed/21940569

[38] Mangla A, Oliveros E, Williams KA et al. Cardiac Imaging in the Diagnosis of Coronary Artery Disease. Curr Probl Cardiol [Internet] 2017; 42: 316 366. doi:http://www.sciencedirect.com/science/article/pii/ S0146280617300725

[39] Hoffmann U, Ferencik M, Udelson JE et al. Prognostic Value of Noninvasive Cardiovascular Testing in Patients With Stable Chest Pain: Insights From the PROMISE Trial (Prospective Multicenter Imaging Study for Evaluation of Chest Pain). Circulation 2017; 135: 2320-2332

[40] Varga-Szemes A, Meinel FG, De Cecco CN et al. CT Myocardial Perfusion Imaging. Am J Roentgenol [Internet] 2015; 204: 487-497. doi:https:// doi.org/10.2214/Am J Roentgenol.14.13546

[41] Branch KR, Haley RD, Bittencourt MS et al. Myocardial computed tomography perfusion. Cardiovasc Diagn Ther [Internet] 2017; 7: 452462. doi:http://www.ncbi.nlm.nih.gov/pmc/articles/PMC5716942/

[42] Danad I, Ó-Hartaigh B, Min JK. Dual-energy computed tomography for detection of coronary artery disease. Expert Rev Cardiovasc Ther [Internet] 2015; 13: 1345-1356. doi:https://www.ncbi.nlm.nih.gov/ pubmed/26549789

[43] Bauer RW, Kerl JM, Fischer N et al. Dual-Energy CT for the Assessment of Chronic Myocardial Infarction in Patients With Chronic Coronary Artery Disease: Comparison With 3-T MRI. Am J Roentgenol [Internet] 2010; 195: 639-646. doi:https://doi.org/10.2214/Am J Roentgenol.09.3849 
[44] Gudrun F, Robert G, André P et al. Adenosine Stress High-Pitch 128-Slice Dual-Source Myocardial Computed Tomography Perfusion for Imaging of Reversible Myocardial Ischemia. Circ Cardiovasc Imaging [Internet] 2011; 4: 540-549. doi:https://doi.org/10.1161/CIRCIMAGING.110.961250

[45] Siontis KC, Gersh BJ, Williamson EE et al. Diagnostic Performance of Myocardial CT Perfusion Imaging With or Without Coronary CT Angiography. JACC Cardiovasc Imaging [Internet] 2016; 9: 322-324. doi:http://www. sciencedirect.com/science/article/pii/S1936878X15002570

[46] Rochitte CE, George RT, Chen MY et al. Computed tomography angiography and perfusion to assess coronary artery stenosis causing perfusion defects by single photon emission computed tomography: the CORE320 study. Eur Heart J 2014; 35: 1120-1130

[47] Osawa K, Miyoshi T, Koyama Y et al. Additional diagnostic value of firstpass myocardial perfusion imaging without stress when combined with 64-row detector coronary $\mathrm{CT}$ angiography in patients with coronary artery disease. Heart 2014; 100: 1008-1015

[48] Wang R, Yu W, Wang Y et al. Incremental value of dual-energy CT to coronary $\mathrm{CT}$ angiography for the detection of significant coronary stenosis: comparison with quantitative coronary angiography and single photon emission computed tomography. Int J Cardiovasc Imaging 2011; 27: 647-656

[49] Ruzsics B, Schwarz F, Schoepf U] et al. Comparison of dual-energy computed tomography of the heart with single photon emission computed tomography for assessment of coronary artery stenosis and of the myocardial blood supply. Am J Cardiol 2009; 104: 318-326

[50] Blankstein R, Shturman LD, Rogers IS et al. Adenosine-induced stress myocardial perfusion imaging using dual-source cardiac computed tomography. J Am Coll Cardiol 2009; 54: 1072-1084

[51] So A, Hsieh J, Narayanan S et al. Dual-energy CT and its potential use for quantitative myocardial CT perfusion. J Cardiovasc Comput Tomogr 2012; 6: 308-317

[52] Lardo AC, Cordeiro MA, Silva C et al. Contrast-enhanced multidetector computed tomography viability imaging after myocardial infarction: characterization of myocyte death, microvascular obstruction, and chronic scar. Circulation 2006; 113: 394-404. doi:https://doi.org/ 10.1161/CIRCULATIONAHA. 105.521450

[53] Kehr E, Sono M, Chugh SS et al. Gadolinium-enhanced magnetic resonance imaging for detection and quantification of fibrosis in human myocardium in vitro. Int ] Cardiovasc Imaging [Internet] 2008; 24: 6168. doi:https://doi.org/10.1007/s10554-007-9223-y

[54] Nacif MS, Kawel N, Lee J] et al. Interstitial Myocardial Fibrosis Assessed as Extracellular Volume Fraction with Low-Radiation-Dose Cardiac CT. Radiology [Internet] 2012; 264: 876-883. doi:https://doi.org/10.1148/ radiol.12112458

[55] Lee HJ, Im D], Youn JC et al. Myocardial Extracellular Volume Fraction with Dual-Energy Equilibrium Contrast-enhanced Cardiac CT in Nonischemic Cardiomyopathy: A Prospective Comparison with Cardiac MR Imaging. Radiology 2016; 280: 49-57

[56] Treibel TA, Fontana M, Steeden JA et al. Automatic quantification of the myocardial extracellular volume by cardiac computed tomography: Synthetic ECV by CCT. J Cardiovasc Comput Tomogr 2017; 11: 221-226

[57] Amano Y, Takayama M, Kumita S. Contrast-enhanced myocardial T1weighted scout (Look-Locker) imaging for the detection of myocardial damages in hypertrophic cardiomyopathy. J Magn Reson Imaging 2009; 30: $778-784$

[58] Han Y, Peters DC, Dokhan B et al. Shorter difference between myocardium and blood optimal inversion time suggests diffuse fibrosis in dilated cardiomyopathy. J Magn Reson Imaging [Internet] 2009; 30 : 967-972. doi:https://doi.org/10.1002/jmri.21953

[59] Palazzuoli A, Cademartiri F, Geleijnse ML et al. Left ventricular remodelling and systolic function measurement with 64 multi-slice computed tomography versus second harmonic echocardiography in patients with coronary artery disease: a double blind study. Eur J Radiol 2010; 73: 82-88
[60] Lewis MA, Pascoal A, Keevil SF et al. Selecting a CT scanner for cardiac imaging: the heart of the matter. $\mathrm{Br}$ ] Radiol [Internet] 2016; 89: 20160376. doi:https://www.ncbi.nlm.nih.gov/pubmed/27302494

[61] Lin E, Alessio A. What are the basic concepts of temporal, contrast, and spatial resolution in cardiac CT? J Cardiovasc Comput Tomogr [Internet] 2009; 3: 403-408. doi:https://www.ncbi.nlm.nih.gov/pubmed/19717355

[62] Seneviratne SK, Truong QA, Bamberg F et al. Incremental diagnostic value of regional left ventricular function over coronary assessment by cardiac computed tomography for the detection of acute coronary syndrome in patients with acute chest pain: from the ROMICAT trial. Circ Cardiovasc Imaging 2010; 3: 375-383

[63] Bauters C, Deneve M, Tricot O et al. Prognosis of Patients With Stable Coronary Artery Disease (from the CORONOR Study). Am J Cardiol [Internet] 2014; 113: 1142-1145. doi:https://doi.org/10.1016/j.amjcard.2013.12.019

[64] Gopalan D. Right heart on multidetector CT. Br J Radiol 2011; 84: S306S323

[65] Guo Y, Gao H, Zhang X et al. Accuracy and reproducibility of assessing right ventricular function with 64-section multi-detector row CT: comparison with magnetic resonance imaging. Int J Cardiol 2010; 139: 254-262

[66] Tee M, Noble JA, Bluemke DA. Imaging techniques for cardiac strain and deformation: comparison of echocardiography, cardiac magnetic resonance and cardiac computed tomography. Expert Rev Cardiovasc Ther 2013; $11: 221-231$

[67] Tee MW, Won S, Raman FS et al. Regional Strain Analysis with Multidetector CT in a Swine Cardiomyopathy Model: Relationship to Cardiac MR Tagging and Myocardial Fibrosis. Radiology [Internet] 2015; 277: 88-94. doi:https://doi.org/10.1148/radiol.2015142339

[68] Eggebrecht H, Mehta RH. Transcatheter aortic valve implantation (TAVI) in Germany 2008-2014: on its way to standard therapy for aortic valve stenosis in the elderly? Eurolntervention J Eur Collab with Work Gr Interv Cardiol Eur Soc Cardiol 2016; 11: 1029-1033

[69] Lehmkuhl L, Foldyna B, Von Aspern K et al. Inter-individual variance and cardiac cycle dependency of aortic root dimensions and shape as assessed by ECG-gated multi-slice computed tomography in patients with severe aortic stenosis prior to transcatheter aortic valve implantation: is it crucial for. Int ] Cardiovasc Imaging [Internet] 2013; 29: 693-703. doi: https://doi.org/10.1007/s10554-012-0123-4

[70] Hell MM, Biburger L, Marwan M et al. Prediction of fluoroscopic angulations for transcatheter aortic valve implantation by $\mathrm{CT}$ angiography: influence on procedural parameters. Eur Heart J Cardiovasc Imaging 2017; 18: 906-914

[71] Bolling SF, Pagani FD, Deeb GM et al. Intermediate-term outcome of mitral reconstruction in cardiomyopathy. J Thorac Cardiovasc Surg 1998; 115: 381-388

[72] Grasso C, Capodanno D, Tamburino C et al. Current status and clinical development of transcatheter approaches for severe mitral regurgitation. Circ ] 2015; 79: 1164-1171

[73] Achenbach S, Delgado V, Hausleiter J et al. SCCT expert consensus document on computed tomography imaging before transcatheter aortic valve implantation (TAVI)/transcatheter aortic valve replacement (TAVR). J Cardiovasc Comput Tomogr [Internet] 2012; 6: 366-380. doi:http:// www.sciencedirect.com/science/article/pii/S1934592512003656

[74] von Aspern K, Foldyna B, Etz CD et al. Effective diameter of the aortic annulus prior to transcatheter aortic valve implantation: influence of area-based versus perimeter-based calculation. Int J Cardiovasc Imaging 2015; 31: 163-169

[75] Zoni-Berisso M, Lercari F, Carazza T et al. Epidemiology of atrial fibrillation: European perspective. Clin Epidemiol 2014; 6: 213-220

[76] Lacomis JM, Wigginton W, Fuhrman C et al. Multi-Detector Row CT of the Left Atrium and Pulmonary Veins before Radio-frequency Catheter Ablation for Atrial Fibrillation. RadioGraphics [Internet] 2003; 23 (Suppl. 1): S35-S48. doi:https://doi.org/10.1148/rg.23si035508 